Please do not remove this page

RMIT

UNIVERSITY

\title{
Are landscape ecologists addressing uncertainty in their remote sensing data?
}

Lechner, Alexander; Langford, William; Bekessy, Sarah; Jones, Simon

https://researchrepository.rmit.edu.au/esploro/outputs/9921859226801341/filesAndLinks?institution=61RMIT_INST\&index=null

Lechner, A., Langford, W., Bekessy, S., \& Jones, S. (2012). Are landscape ecologists addressing uncertainty in their remote sensing data? Landscape Ecology, 27(9), 1249-1261.

https://doi.org/10.1007/s10980-012-9791-7

Document Version: Accepted Manuscript

Published Version: https://doi.org/10.1007/s10980-012-9791-7

Repository homepage: https://researchrepository.rmit.edu.au

(c) Springer Science+Business Media B.V. 2012

Downloaded On 2023/04/26 22:27:21 +1000

Please do not remove this page 
Thank you for downloading this document from the RMIT Research Repository.

The RMIT Research Repository is an open access database showcasing the research outputs of RMIT University researchers.

RMIT Research Repository: http://researchbank.rmit.edu.au/

\section{Citation:}

Lechner, A, Langford, W, Bekessy, S and Jones, S 2012, 'Are landscape ecologists addressing uncertainty in their remote sensing data?', Landscape Ecology, vol. 27, no. 9, pp. 1249-1261.

See this record in the RMIT Research Repository at:

https://researchbank.rmit.edu.au/view/rmit:20576

Version: Accepted Manuscript

\section{Copyright Statement:}

(C) Springer Science+Business Media B.V. 2012

\section{Link to Published Version:}

http://dx.doi.org/10.1007/s10980-012-9791-7 


\section{Are Landscape Ecologists addressing uncertainty in their remote sensing data?}

Alex M. Lechner, William T. Langford, Sarah. A. Bekessy and Simon. D. Jones

A. M. Lechner (Corresponding author)

Centre for Mined Land Rehabilitation, Sustainable Minerals Institute, University of Queensland, Sir James Foots Building, Cnr Staff House and College Roads, St Lucia, QLD, 4072

e-mail: a.lechner@uq.edu.au

phone: 61-401-233-019/fax:61-7-3346-4021

A. M. Lechner (Corresponding author) • W. T. Langford • S. D. Jones

School of Mathematical and Geospatial Sciences, RMIT University, GPO Box 2476V, Melbourne, VIC, 3001, Australia

\section{S. A. Bekessy}

School of Global Studies, Social Science \& Planning, RMIT University, GPO Box 2476V, Melbourne, VIC, 3001, Australia

Date of the manuscript draft: December, 2010

Manuscript word count (including text, references, tables, and captions; not including title page): 7500 


\section{Abstract}

In this quantitative review, we investigate the degree to which landscape ecology studies that use spatial data address spatial uncertainty when conducting analyses. We identify three broad categories of spatial uncertainty that are important in determining the characterisation of landscape pattern and affect the outcome of analysis in landscape ecology: i) classification scheme uncertainty, ii) spatial scale and iii) classification error. The second category, spatial scale, was further subdivided into five scale dependent factors i) pixel size ii) minimum mappable unit, iii) smoothing, iv) thematic resolution and v) extent. We reviewed all articles published in the journal Landscape ecology in 2007 and recorded how spatial data was used and whether spatial uncertainty was addressed or reported in ecological analyses.

This review found that spatial uncertainty was rarely addressed and/or reported. Most articles used the default pixel size of the sensor. Only $23 \%$ of articles addressed one or more scale dependent factors and $47 \%$ reported one or more as issues. A single study of the 59 investigated the effect of classification accuracy on ecological analyses. We demonstrate that spatial uncertainty is not being addressed as standard practice in analyses in landscape ecology, and then describe methods to test for spatial uncertainty and potential solutions that can be developed in the future.

Keywords: Scale, spatial uncertainty, classification error, landscape pattern, remote sensing, GIS, land-cover mapping 


\section{Introduction}

The use of thematic data derived from remote sensing is common in landscape ecology due to its wide availability, total sample, broad coverage and ecologically relevant spectral bands (Fassnacht et al. 2006; Gergel 2007). Remote sensing data processed using a geographic information system (GIS) is the most common form of data used to describe land cover in order to investigate the relationship between landscape pattern and ecological processes (Chen et al. 2008; Metzger 2008). However, it can be misused or used without an understanding of its limitations due to its availability and the ease which software can process remote sensing data, (Fassnacht et al. 2006; Gergel 2007). Maps derived from remote sensing data are often treated as the absolute truth (Adams and Gillespie 2006; Evans 1997), despite the uncertainty and error that is always present when simplifying and generalising the complexity of real world geographic phenomena (Kardos et al. 2006) (Figure 1).

$<$ Figure 1 >

Within the ecological literature there are numerous studies describing the effects of spatial uncertainty on ecological analyses. Some commonly known sources of spatial uncertainty, such as grain and extent, have been recognized for decades and are documented in landscape ecology textbooks (Gergel and Turner 2001; Turner et al. 2001), but we contend that these effects are not routinely tested for in landscape ecology. This study first reviews the ecological and spatial sciences literature to describe the range of spatial uncertainty. We then systematically quantify the proportion of landscape ecology studies that address and/or acknowledge spatial uncertainty, using a subset of the studies published in the journal Landscape Ecology to assess whether testing for these factors is routine. We specifically look at three wellknown sources of spatial uncertainty that are proven to affect spatial analyses: i) 
classification schemes, ii) spatial scale, and iii) classification error. Finally, we conclude with a brief discussion of possible solutions to address the effects of spatial uncertainty on ecological analyses.

\section{Methods}

An initial survey of the ecological and spatial science literature was conducted to identify key remote sensing spatial uncertainty issues that influence the outcome of ecological analyses. We focused on issues that affect the characterisation of landscape pattern using remote sensing data, such as land use and land cover datasets (LULC).

As an analogue for the landscape ecology community, this study reviewed all the research articles published in the journal Landscape Ecology in 2007 (n=101) to assess whether addressing spatial uncertainty issues is a routine practice. An alternative review method using a search in Scopus on the term "Landscape ecology" was found to be less consistent in identifying relevant articles. For each article, we recorded how landscape ecologists used spatial data and whether spatial uncertainty issues were addressed and reported. We did not make qualitative judgements of how effective the studies were. This study only reviewed articles that used remote sensing data, which was considered to include aerial and satellite derived imagery. Simulated spatial data was not included as it is assumed that articles using simulated represent landscapes with $100 \%$ accuracy at the appropriate scale. Of the original 101 articles reviewed, 15 articles were not included due to inadequate information describing spatial data (Table 1).

$<$ Table 1>

This review found that of the articles in Landscape Ecology in 2007 only $69 \%$ $(n=86)$ had adequate information describing the type of data used or were not review articles. Additionally, 15\% used only GIS data and 16\% used neither GIS nor remote 
sensing data (Table 1). Hereafter, the review only investigates the articles that contained remote sensing data $(n=59)$.

\section{Results and Discussion}

\section{Classification Scheme uncertainty}

In landscape ecology the dominant geographic representation of landscapes is discrete patches of habitat surrounded by non-habitat (such as farmlands or urban areas), also known as a matrix or mosaic of patch types. This study found that discrete classification schemes were the dominant models used to represent land cover in landscape ecology, with $25 \%$ of the articles reviewed using a binary classification scheme and $68 \%$ using a multi-class classification scheme (Table 1). However, many alternative methods are available to represent landscapes, such as point based and continuous field data and fuzzy sets (Gustafson 1998; Robinson 2007). This review found that these alternative methods were rarely used. Gridded data with continuous values were the only non-discrete classification scheme recorded (12\%). These alternative classification methods can be used to reduce the effect of spatial uncertainty arising from classifying complex natural objects into simple discrete classes.

Using discrete classification systems in ecological analyses can result in spatial uncertainty as there are often no definite boundaries between land cover classes and/or patches. Thus, there is nearly an infinite number of ways to classify the landscape using a discrete classification system (Arnot et al. 2004; Burrough 1996; Schmit et al. 2006) and boundaries between classes can be subjective and artificial (Chapman et al. 2005; Powell et al. 2004). Using a discrete classification scheme that does not incorporate a range of sub-pixel variation will affect analyses such as the calculation of class areal extent (Foody 1996) and landscape metrics describing vegetation pattern (Arnot et al. 2004). 
Another source of spatial uncertainty from using remote sensing data that occurs regardless of the type of classification scheme is the imprecise nature of landcover classes. The characterisation of landscape pattern depends on the system property being measured and the classification scheme used (Comber et al. 2005b; Congalton and Green 1993; Li and Wu 2004). The imprecise specification of landcover classes means that, even if the same class labels are used in maps produced by two different people, these classes will not necessarily be equivalent (Comber et al. 2005b). Differences in classification schemes and class description will affect the outcome of spatial analyses using remote sensing data (e.g. Colson et al. 2009; Cunningham 2006; Manton et al. 2005), potentially making the results inaccurate or spurious.

The imprecise nature of landcover classes and differences between classification schemes is an important consideration, especially when using readily available datasets that may not be specifically developed to address ecological phenomena. Readily available datasets are popular due to their availability and their low cost in comparison to developing new project specific maps (Comber et al. 2005a). Approximately 36\% of articles reported using generic LULC datasets produced by a third party, such as Europe's CORINE dataset or the US's national land cover dataset (NLCD) (Table 1). Furthermore, 33\% of articles using generic datasets aggregated LULC datasets to reduce the number of land cover classes, often to create binary land cover maps. Approximately $17 \%$ of all articles aggregated multi-class data to a smaller number of classes. The aggregation of land cover classes introduces further uncertainty as the rules for aggregating classes can be somewhat arbitrary (Quaife et al. 2008). For example, combining LULCs that are classified using floristics to new classes based on structure (e.g. open/closed forest) will result in ambiguity for those vegetation types that do not neatly fit into the structural classes. The effects of aggregating classes in other cases, 
however, have been shown to result in higher accuracy classes when thematic resolution was lowered (Remmel 2009).

\section{Spatial Scale}

The concept of scale can be considered in terms of the scale dependency of the pattern-process relationship as well as the method used to sample ecological phenomena. In this study the word scale is used as an overarching term that can be subdivided into three categories: operation, observation and analysis scale (Dungan et al. 2002).

The operation scale (also known as the ecological or characteristic or intrinsic scale) describes the scale at which the phenomenon (i.e. organism) interacts with or perceives the landscape (Dungan et al. 2002; Wu and Li 2006). This concept is related to hierarchy theory, which describes the organisation of ecological systems into relatively isolated distinct operational scales (O'Neill et al. 1989). While there may be just one correct scale at which to measure a phenomenon, there are cases where phenomena act at multiple scales and therefore need to be measured at multiple scales (Chen et al. 2008; Levin 1992; Wiens 1989; Wu et al. 2006). Typically, little is known about the operation scale (Holland et al. 2004; Mayer and Cameron 2003). However, some phenomena may be scale invariant (Wu et al. 2006) or mathematically predictable and thus scalable (Saura and Castro 2007).

In practice, a phenomenon cannot be measured directly and our understanding of it is affected by the analysis and observation scale. The observation scale (also known as sampling or measurement scale) describes the size, shape, extent and distance between observational units used to sample a phenomenon. The analysis scale (or in some cases modelling scale) refers to the units that are used in analyses (Dungan et al. 
2002; Wu and Li 2006). Within landscape ecology the analysis scale is often patches or landscapes while the observation scale is generally the pixel size (Figure 2).

$<$ Figure 2>

The analysis and observation scales can change as a result of a number scale dependent factors relating to all aspects of the creation of spatial data, from the sensor used to post-processing and data analysis methods (Figure 3). The survey of the literature identified five scale-dependent factors as important in determining the characterisation of landscape pattern and affect the outcome of analysis in landscape ecology i) pixel size ii) minimum mappable unit (MMU), iii) smoothing, iv) thematic resolution and $\mathrm{v}$ ) extent. The first four factors affect observation scale and the fifth affects analysis scale.

$<$ Figure 3>

\section{Observation scale}

Spatial resolution is made up of several scale dependent factors, including pixel size, MMU, and smoothing. The spatial resolution is the primary factor influencing the classification of remote sensing data and limits the smallest identifiable area (Tatem et al. 2002; Woodcock and Strahler 1987). In raw unprocessed raster data, spatial resolution is often considered to be equivalent to pixel size (Atkinson 2004). The value of a pixel is predominantly determined by land cover corresponding to its location (Cracknell 1998). However, the true spatial resolution is greater than the pixel size as its value is affected by land cover found in neighbouring pixels due to the characteristics of remote sensing devices (Cracknell 1998; Fisher 1997).

In some cases, LULC maps are processed so that the spatial resolution of the image is coarsened through the imposition of a MMU. The MMU is the smallest area in the extent that will be mapped as a discrete unit (Fassnacht et al. 2006; Saura 2002). As 
the MMU is larger than the pixel size, detail contained in the original mapping unit is lost (Saura 2002). MMUs are often imposed to increase classification accuracy or decrease the complexity of a map and increase legibility of the cartographic representation of the landscape (European Environment Agency 1994; Saura 2002).

The pixel size and MMU define the physical area on the ground that is sampled. However, pre and post-processing of a remote sensing image using smoothing filters or resampling increases the influence of the values of the neighbouring pixels and thus decreases spatial resolution. Smoothing filters such as a low pass or majority filter are commonly used in remote sensing to increase classification accuracy or to remove noise caused by sensor error in raw remote sensing data (Ivits and Koch 2002; Zukowskyj et al. 2001) while, resampling is often used for image registration.

The final aggregation factor, thematic resolution, describes the level of classification detail of the sampling units, otherwise known as attribute precision (Cunningham 2006) or categorical resolution (Franklin and Woodcock 1997). For example, the Anderson classification scheme contains 4 resolutions with each higher resolution class nested in a lower level class, e.g., Residential nested within Urban. The exclusion or inclusion of different land cover classes will affect the representation of spatial pattern. Both the thematic resolution and MMU were only reported in articles that used thematic/categorical datasets (91\% of articles reviewed) as these scale dependent factors are not relevant to continuous data.

The four factors that make up observation scale (pixel size, MMU, smoothing and thematic resolution) are important in determining the characterisation and the accuracy of landscape pattern and its components such as patches and corridors. Decreasing the resolution of the observation scale (i.e., larger pixels, larger MMU, etc.) all have similar effects on characterising landscape structure-reducing fine scaled 
fragmentation. This has been shown for each factor: pixel size (Wu 2004; Wu et al. 2002), smoothing (e.g. Lechner et al. 2008; Thompson and Gergel 2008), MMU (Kendall and Miller 2008; Thompson and Gergel 2008) and thematic resolution (Buyantuyev et al. 2010; Buyantuyev and Wu 2007; Castilla et al. 2009). When observation scale is coarse, small patches will not be extracted (Fassnacht et al. 2006; Lechner et al. 2009), the spatial extent and configuration of patches will change (Thompson and Gergel 2008), edge complexity will decrease (i.e. edge to area length decreases) (Kendall and Miller 2008), and landscapes will be represented as large homogenous areas that in reality may not exist (Corry and Nassauer 2005; Stohlgren et al. 1997). Ecologically important small and linear features such as corridors are more likely to be mapped inaccurately or be absent from a landscape (Lechner et al. 2009). While landscape composition is affected by all aggregation factors, thematic resolution directly affects landscape composition through reducing the number of patch types (Corry and Nassauer 2005). These factors indirectly affect landscape composition through the loss of rare land cover types that tend to be found in small patches (Smith et al. 2002; Thompson and Gergel 2008). Thompson and Gergel (2008) found estimates of rare forest classes differed by as much as $36 \%$, and that the mean patch size increased by $650 \%$ due to the application of a smoothing filter.

The observation scale not only affects the accuracy of remote sensing classifications (Smith et al. 2003; Woodcock and Strahler 1987) but also affects ecological analyses rely on them (c.f. modifiable areal unit problem). Spatial resolution has been demonstrated to affect statistical analyses such as inference about population mean, variation, and statistical significance (Pontius Jr et al. 2005; Stoms et al. 1992). Changing scale can affect the output of ecological models such as multivariate analysis, by changing the variables included in a model, the relative importance of those 
variables and the complexity of the models (Karl et al. 2000; Lawler et al. 2004). The effects of spatial resolution and, to a lesser degree, thematic resolution have been shown for other types of analysis such as measuring land cover proportions (Moody and Woodcock 1994; Smith et al. 2002), landscape metrics that measure fragmentation (Buyantuyev and Wu 2007; Wickham and Riitters 1995; Wu et al. 2000), graph-based metrics that identify critical habitat patches for the maintenance of landscape connectivity (Pascual-Hortal and Saura 2007; Rae et al. 2007), and analyses that investigate the change in landscape composition over time (Pontius et al. 2008).

\section{Analysis scale}

The analysis scale is a property of the geographic extent of the analysis units and the landscape components that are measured with those spatial units. The scale dependent factor extent (also known as geographic scale) refers to the size of the study area or the total area mapped (Changyong and Lam 1997; Turner 1989). Within a study area the type of spatial organisational unit can be a patch, site, or landscape for discrete data types. Studies that conducted patch-level analyses compared patch measurements (e.g., patch area or shape) to ecological phenomena (e.g., species diversity) for each patch or a sample of patches within a landscape (Figure 4). Studies which used site-level analyses (i.e. core area or neighbourhood area or plot) related ecological variables measured at a single point or plot (e.g. trap counts) to environmental measurements calculated for the surrounding area. For studies with landscapes as the organisational unit, the comparison was either between multiple landscapes in different locations or the same landscape at different times (Figure 4). The most common analysis scale was the landscape, used in 53\% of articles (Table 1). In some of the articles reviewed, more than one analysis scale was used (e.g. Debuse et al. 2007; Gustafson et al. 2007). 
Uncertainty associated with using a specific extent is a result of the sometimes arbitrary location of boundaries, affecting the characterisation of landscape pattern and the outcome of ecological analyses. Landscape pattern will change with extent, as landscapes may appear fragmented at one extent and continuous at other extents (Cushman and McGarigal 2008). For example, Turner (1989) found that measures of diversity remained constant until the extent boundaries crossed natural boundaries (i.e. catchment boundary). Once the natural boundary was crossed, there was a rapid increase in diversity then it remained constant until the next boundary. As extent increases so does the probability of sampling rare classes (Riitters et al. 2000; Wiens 1989). Furthermore, extent can affect landscape pattern through artificially truncating patches that occur at the boundary (Cushman and McGarigal 2008; 0'Neill et al. 1996). Changing extent can affect ecological analyses because it can influence the inclusion of abiotic and biotic processes in a study area. As with aggregation factors, changing extent will affect analyses such as measurements of landscape pattern (Buyantuyev et al. 2010; O'Neill et al. 1996; Townsend et al. 2009), graph based connectivity metrics (PascualHortal and Saura 2007) and statistical analysis (Chapman et al. 2005; Hess et al. 2006; Wu et al. 1997).

\section{Do landscape ecologists routinely address scale dependent factors?}

This review determined that only $39 \%$ of the articles reviewed addressed one or more scale dependent factors and only $47 \%$ reported one or more as issues (Figure 5). The studies that addressed one or more scale dependent factors commonly did this through testing the sensitivity of the results of their analyses to a range of scales, for example by varying pixel size. Only $8 \%$ of articles addressed grain (pixel size or MMU) and $25 \%$ addressed extent, which is surprisingly low considering these two type of scale dependent factors appear to be the most prominent factors discussed in the 
landscape ecology and ecological literature (Table 1) (e.g. Mayer and Cameron 2003; Turner 2005). The most common form of spatial uncertainty addressed was in testing for uncertainty in the scale of the analysis at the site level, conducted in $59 \%$ of site level studies, commonly using multiple buffer sizes.

$<$ Figure 5>

Most studies used the pixel size of the raw remote sensing image within their analyses, with the exception of those that specifically addressed scale issues by conducting multi-scale studies. $46 \%$ of the papers reviewed used Landsat data which has a 30 m pixel size for most bands of both TM and ETM+ sensors (one study used Landsat MSS which has an $80 \mathrm{~m}$ pixel size). 53\% used aerial imagery with a pixel size less than $1 \mathrm{~m}$ (Table 1). The small range of pixel sizes used suggests the choice of scale is largely driven by the available data and the cost in acquiring and classifying it (Chen 2008; Comber 2008; Gergel 2007). Papers that addressed scale through multi-scale studies typically addressed only one single scale-dependent factor, despite the multifaceted nature of scale (Lechner et al. 2008).

\section{Classification Error}

Classification error refers to the difference between the label assigned on a classified remote sensing map and the real value on the ground. Classification error is generated at different stages of the production of remote sensing maps, affecting the representation of land cover (Friedl et al. 2001). The quantification of classification error is typically based on a confusion matrix (also known as an error or agreement matrix) and is considered fundamental to accuracy assessment (Congalton 1988; Foody 2002). The confusion matrix describes the accuracy of each land cover class and the relative rates of misclassifications for each pair of classes (Congalton 1993). Studies that make use of a remote sensing land cover dataset should as a minimum include a 
classification accuracy assessment (Cunningham 2006). A statement of accuracy of the data is important as it conveys to the reader some indication of the reliability of the data their results rely on. This review found that only $5 \%$ of studies included a confusion matrix. However, $36 \%$ of all studies used generic datasets which are likely to be associated with published material elsewhere describing accuracy assessment results.

High accuracy biophysical input maps derived from remote sensing are considered important requirements for ecological analyses such as habitat models (Guisan and Zimmermann 2000). While accuracy assessment using confusion matrices is important, the spatial distribution of errors (e.g., whether erroneous pixels are found more often in smaller patches) may also need consideration (Congalton 1988). Furthermore, classification error can be magnified when propagated into a model (Gergel et al. 2007). For example, Langford et al. (2006) found that in certain situations classification error can cause a thousand-fold increase in error in the calculation of landscape metrics. Gergel et al. (2007) suggested that it is important to describe not only the magnitude of errors but also the implication of the errors. This review found only 1 of the studies reviewed tested for the effect of classification error on analysis.

\section{Addressing spatial uncertainty}

In our review of 2007 Landscape Ecology papers, we found four strategies for addressing spatial uncertainty: i) not reporting, ii) reporting without testing, iii) testing for the effect of one or more spatial uncertainty source (commonly through sensitivity analyses) and iv) developing methods to address a single source of spatial uncertainty. Strategy (i) was the most common with $53 \%$ of the articles reviewed failing to report potential scale issues and $81 \%$ failing to report classification error issues. Furthermore, many articles provided very little documentation on the source of the spatial data and the processing used. In some cases, it is possible that the scale of the dataset may have 
been appropriate for the organism/s in question by default, or that the classification error levels may have been low enough to not affect analyses but the lack of reporting makes that impossible to determine. It is also possible that some authors may have failed to discuss these issues in a manuscript due to space requirements, even if they had been explored in the actual research.

Of papers that tested for spatial uncertainty (strategy iii), all but one investigated issues of scale (97\%); and in those cases, the investigation of spatial uncertainty was the focus the paper as opposed to being addressed as part of a robust ecological analysis. That is, these studies specifically focused on testing scale dependent ecological patterns. The lack of testing is likely because of the absence of clearly defined rules for dealing with spatial uncertainty when developing ecological models (Chen 2008). Furthermore, the solutions to spatial uncertainty issues that are developed are unique to the specific combination of form of spatial uncertainty, ecological model, and the ecological phenomenon being investigated. In what follows, we detail recommendations for contending with spatial uncertainty.

Recommendations to contend with spatial uncertainty

To conduct robust ecological analyses based on spatial data, we need to know and/or reduce the error and uncertainty in the analytical process. This first requires that we measure and state the consequences of uncertainty as well as take steps to reduce its harmful effects. There are several components to addressing spatial uncertainty: i) identify and explain scale dependent factors, ii) sensitivity analysis, and iii) solution to specific types of spatial uncertainty. Addressing spatial uncertainty is a multi-faceted task of which some aspects of the task are well-understood and others are topics for continuing research. This section ends with a recommendation for future research that is required to develop a generalised solution to spatial uncertainty. 
Identify and explain scale dependent factors

Studies that conduct spatial analysis should include i) a list and explanation of the scale dependent factors associated with the data (i.e. MMU, extent, etc.), ii) a description of the scale at which the ecological phenomenon perceives the landscape, iii) the appropriateness of the classification scheme used, iv) an error matrix, and v) explicit definition of all scale dependent factors. This last point is important because many articles examined in this study used scale as a generic term but failed to qualify its meaning explicitly, consistent with previous findings (King 1991; Vermaat et al. 2005). Sensitivity analysis

Given that the true amount and nature of error due to uncertainty is unknown, researchers need to do a sensitivity analysis of the outcomes resulting from the range of spatial uncertainties and input errors identified earlier. Sensitivity analyses of model output to a range of spatial errors should be viewed as a minimum when spatial data is used as input to a spatially explicit model. For the results of the output of an analysis to be valid, the outcome should be robust to variation resulting from various sources of spatial uncertainty.

There are numerous forms of spatial uncertainty; too numerous to be routinely evaluated individually. Researchers need to consider the ranges of variation tested for in a sensitivity analysis. What is the largest and smallest pixel size that should be tested? Expert opinion and literature review can be used to guide the selection of the types of spatial uncertainty to be tested for in sensitivity analyses. For example, when modelling the movement of kangaroos across a catchment, vegetation maps derived from $30 \mathrm{~m}$ Landsat imagery are likely to describe the spatial distribution of habitat patches suitably. However, smaller mammals such as bandicoots are likely to use patches 
smaller than the $30 \mathrm{~m}$ pixel size. Thus, the effects of pixel size on the amount of habitat or total number of patches would need to be evaluated.

Some kinds of spatial uncertainty such as ambiguity in classification schemes may only be practical to test with a subset of the data. For example, the robustness of an analysis to a particular classification scheme may be tested with more accurate, but time consuming to produce field based mapping and compared to generic remote sensing data for a subset of the study area.

\section{Solutions to spatial uncertainty}

The simplest solution for some ecological problems where knowledge of species ecology is present will be to use imagery with i) finer spatial resolution than the phenomena of interest, ii) extent larger than the ecological process of interest, and iii) a MMU that eliminates patches too small to be relevant to the question at hand. These measures, along with more accurate classification methods and a classification scheme specific to the ecological phenomenon being analysed, can reduce some of the known potential sources of spatial uncertainty. However, more complex dynamic ecological processes, such as those driven by multiple unknown operation scales, will require the development of more complex methods to identify the appropriate scale(s), classification scheme, and acceptable levels of classification accuracy (See Lechner et al. 2012 for an analysis of the robustness of multi-scale studies to spatial uncertainty).

In some cases uncertainty is unavoidable and techniques to address spatial uncertainty need to be used and/or developed. Already existing techniques for addressing spatial uncertainty are found more widely in the remote sensing and spatial science community. An example of this is the use of fuzzy classification schemes that are not patch based (Robinson 2007). In most cases though, these solutions tend to address a single form of spatial uncertainty and are often tailored to a given ecological model. 
For example, Saura and Castro (2007) described scaling functions for making subpixel landscape metric estimates. The results from the sensitivity analysis as well as knowledge of species ecology need to be used guide the types of spatial uncertainty that need to be addressed. However, using current methods available described above there will always be untested and unaddressed forms of spatial uncertainty.

Development of a generalised spatially explicit error models

The development of a generalised spatially explicit error model is required to describe the uncertainty in the relationship between the observation of ecological phenomenon and the outcome of analyses. Since spatial error does not follow commonly used error assumptions (e.g., zero mean, independent, normally distributed), alternate, spatially explicit error models are necessary for generating reasonable stochastic variants in sensitivity analysis. We know and can model many ways that data can be damaged and/or distorted. Applying models of these errors (and their interactions) to data can allow users to then evaluate their consequences for our ecological inferences and decisions.

Part of the solution may lie in the use of the virtual ecologist approach (Zurell et al. 2010) where simulated data are used to mimic real phenomenon and the manner in which they are 'virtually' observed. The virtual ecologist approach can also utilise the null landscape model concept (Gardner and Urban 2007) for the simulation of virtual landscapes to test whether observed patterns are structured by stochastic factors or even non-stochastic/biased factors that are due to spatial uncertainty. For example, Fortin et al. (2003) demonstrated how spatial stochastic models could be used to provide confidence intervals for landscape metric estimates through simulating different realisations of landscape based on the spatial autocorrelation and proportion of habitat of a range of landscapes. 


\section{Conclusion}

This review reveals that the assumptions, generalisations, and errors that occur when using spatial data are not being routinely addressed by ecologists (Chapman et al. 2005; Nelson 2001). Spatial uncertainty needs to be addressed as it affects the characterisation of landscape pattern, which may result in failing to uncover a relationship that exists or deriving spurious relationships. The complexity of collecting, processing and classifying imagery and a lack of standard techniques for incorporating spatial uncertainty into ecological analyses mean that addressing these issues is nontrivial. Many map users only deal with final remote sensing products such as generic land cover maps (Schmit et al. 2006; Turner et al. 2001) and are unfamiliar with the computational methods used to create this. The many resulting forms of spatial uncertainty can reduce the robustness of landscape ecological analyses, but the approaches described above may assist in our efforts to improve our understanding of ways to address this uncertainty. However, by continuing to routinely ignore spatial uncertainty, we risk being what Hall (1988) described as a "discipline [that has] been far too eager to grasp at data that appear superficially to support our most cherished beliefs" even though the "data [has] been trying to tell us something quite different".

\section{Acknowledgements}

This work was supported by the Australian Research Council's (ARC) discovery grant DP0450889, the ARC linkage grant LP0882780 and the Australian Commonwealth Environment Research Fund Landscape Logic research hub. Thanks to Patrick Audet and Phillippa Bricher for feedback on the paper. A special thanks to the editor Sarah Gergel and the anonymous reviewers for detailed and constructive feedback on the manuscript.

\section{References}


Adams JB, Gillespie AR (2006) Remote Sensing of Landscapes with Spectral Images A Physical Modeling Approach. Cambridge University Press, NY

Arnot C, Fisher PF, Wadsworth R, Wellens J (2004) Landscape metrics with ecotones: Pattern under uncertainty. Landsc. Ecol. 19(2):181-195

Atkinson PM (2004) Resolution manipulation and sub-pixel mapping. In: De Jong S. M. andVan der Meer F. D. (eds), Remote sensing data analysis: Including the spatial domain. Springer Netherlands, pp. 51-70

Burrough PA (1996) Natural Objects with Indeterminate Boundaries. In: Burrough P. A. andFrank A. U. (eds), Spatial Conceptual Models for Geographic Objects with Undetermined Boundaries. Taylor Francis, London, pp. 3-28

Buyantuyev A, Wu J, Gries C (2010) Multiscale analysis of the urbanization pattern of the Phoenix metropolitan landscape of USA: Time, space and thematic resolution. Landsc. Urban Plann. 94(3-4):206-217

Buyantuyev A, Wu JG (2007) Effects of thematic resolution on landscape pattern analysis. Landsc. Ecol. 22(1):7-13

Castilla G, Larkin K, Linke J, Hay G (2009) The impact of thematic resolution on the patch-mosaic model of natural landscapes. Landsc. Ecol. 24(1):15-23

Changyong C, Lam NS-N (1997) Understanding the Scale and Resolution Effects in Remote Sensing and GIS. In: Quattrochi D. A. andGoodchild M. F. (eds), Scale in Remote Sensing and GIS Eds. Boca Raton, FL: CRC Lewis, 1997. 3-26. CRC Lewis, FL: Boca Raton, pp. 3-26

Chapman A, Muñoz M, Koch I (2005) Environmental Information: Placing Biodiversity Phenomena in an Ecological and Environmental Context. Biodiversity Informatics 2:24- 
Chen J (2008) Ecological Modelling and Perspectives of Forest Landscapes. In:

Lafortezza R., Sanesi G., Chen J., Crow T. R. (eds), Patterns and Processes in Forest Landscapes. Springer Netherlands, pp. 265-270

Chen J, Brosofske KD, Lafortezza R (2008) Ecology and Management of Forest Landscapes. In: Lafortezza R., Sanesi G., Chen J., Crow T. R. (eds), Patterns and Processes in Forest Landscapes. Springer Netherlands, pp. 3-16

Colson F, Bogaert J, Filho AC, Nelson B, Pinagé ER, Ceulemans R (2009) The influence of forest definition on landscape fragmentation assessment in Rondônia, Brazil. Ecological Indicators 9(6):1163-1168

Comber A, Fisher P, Wadsworth R (2005a) What is land cover? Environment and Planning B: Planning and Design 32(2):199-209

Comber A, Fisher P, Wadsworth R (2005b) You know what land cover is but does anyone else? an investigation into semantic and ontological confusion. Int. J. Remote Sens. 26(1):223-228

Comber AJ (2008) The separation of land cover from land use with data primitives. Journal of Land use Science 3(4):215-229

Congalton RG (1988) Using Spatial Auto-Correlation Analysis to Explore the Errors in Maps Generated from Remotely Sensed Data. Photogrammetric Engineering and Remote Sensing 54(5):587-592

Congalton RG, Green K (1993) Practical look at the sources of confusion in error matrix generation. Photogrammetric Engineering and Remote Sensing 59(5):641-644 Corry RC, Nassauer JI (2005) Limitations of using landscape pattern indices to evaluate the ecological consequences of alternative plans and designs. Landsc. Urban Plann. 72(4):265-280 
Cracknell AP (1998) Review article Synergy in remote sensing-what is in a pixel? Int. J. Remote Sens. 19(11):2025 - 2047

Cunningham MA (2006) Accuracy assessment of digitized and classified land cover data for wildlife habitat. Landsc. Urban Plann. 78(3):217-228

Cushman SA, McGarigal K (2008) Landscape Metrics, Scales of Resolution. In: Gadow K. v. andPukkala T. (eds), Designing Green Landscapes. Springer, pp. 33-51

Debuse VJ, King J, House APN (2007) Effect of fragmentation, habitat loss and withinpatch habitat characteristics on ant assemblages in semi-arid woodlands of eastern Australia. Landsc. Ecol. 22(5):731-745

Dungan JL, Perry JN, Dale MRT et al (2002) A balanced view of scale in spatial statistical analysis. Ecography 25(5):626-640

European Environment Agency (1994) CORINE Land Cover. Commission of the European Communities, pp. 1-163

Evans BJ (1997) Dynamic display of spatial data-reliability: Does it benefit the map user? Computers \& Geosciences 23(4):409-422

Fassnacht KS, Cohen WB, Spies TA (2006) Key issues in making and using satellitebased maps in ecology: A primer. For. Ecol. Manag. 222(1-3):167-181

Fisher P (1997) The pixel: a snare and a delusion. Int. J. Remote Sens. 18(3):679 - 685 Foody GM (1996) Fuzzy modelling of vegetation from remotely sensed imagery. Ecol. Model. 85:3-12

Foody GM (2002) Status of land cover classification accuracy assessment. Remote Sens. Environ. 80(1):185-201

Fortin MJ, Boots B, Csillag F, Remmel TK (2003) On the role of spatial stochastic models in understanding landscape indices in ecology. Oikos 102(1):203-212 
Franklin J, Woodcock CE (1997) Multiscale Vegetation Data fo the Mountains of Southern California: Spatial and Categorical Resolution. In: Quattrochi D. A. andGoodchild M. F. (eds), Scale in Remote Sensing and GIS CRC Lewis, FL: Boca Raton, pp. 3-26

Friedl MA, McGwire KC, McIver DK (2001) An overview of uncertainty in optical remotely sensed data for ecological applications. . In: Hunsaker C. T., Goodchild M. F., Friedl M. A., Case T. J. (eds), Spatial Uncertainty in Ecology: Implications for remote sensing and GIS applications. Springer-Verlag, New York, pp. 258-283 Gardner RH, Urban DL (2007) Neutral models for testing landscape hypotheses. Landsc. Ecol. 22(1):15-29

Gergel S, Stange Y, Coops N, Johansen K, Kirby K (2007) What is the Value of a Good Map? An Example Using High Spatial Resolution Imagery to Aid Riparian Restoration. Ecosystems 10(5):688-702

Gergel SE (2007) New Directions in Landscape Pattern Analysis and Linkages with Remote Sensing. In: Wulder M. A. andFranklin S. E. (eds), Understanding forest disturbance and spatial pattern: remote sensing and GIS Approaches. Talyor and Fracis Group, Boca Raton, FL, pp. 173-208

Gergel SE, Turner MG (2001) Learning Landscape Ecology: A Practical Guide to Concepts and Techniques. Springer-Verlag, NY

Guisan A, Zimmermann NE (2000) Predictive habitat distribution models in ecology. Ecol. Model. 135(2-3):147-186

Gustafson EJ (1998) Minireview: Quantifying Landscape Spatial Pattern: What Is the State of the Art? Ecosystems 1(2):143-156 
Gustafson EJ, Lytle DE, Swaty R, Loehle C (2007) Simulating the cumulative effects of multiple forest management strategies on landscape measures of forest sustainability. Landsc. Ecol. 22(1):141-156

Hall CAS (1988) An assessment of several of the historically most influential theoretical models used in ecology and of the data provided in their support. Ecol. Model. 43(12):5-31

Hess GR, Bartel RA, Leidner AK et al (2006) Effectiveness of biodiversity indicators varies with extent, grain, and region. Biol. Conserv. 132(4):448-457

Holland JD, Bert DG, Fahrig L (2004) Determining the Spatial Scale of Species Response to Habitat. Bioscience 54:227-233

Ivits E, Koch B (2002) Landscape connectivity studies on segmentation based classification and manual interpretation of remote sensing data. eCognition User Meeting, October 2002, München

Kardos J, Moore A, Benwell G Expressing attribute uncertainty in spatial data using blinking regions. In: Caetano M. andPainho M. (eds) 27th International Symposium on Spatial Accuracy Assessment in Natural Resources and Environmental Sciences., 2006. Karl JW, Heglund PJ, Garton EO, Scott JM, Wright NM, Hutto RL (2000) Sensitivity of Species Habitat-Relationship Model Performance to Factors of Scale. Ecol. Appl. 10(6):1690-1705

Kendall MS, Miller T (2008) The influence of thematic and spatial resolution on maps of a coral reef ecosystem. Marine Geodesy 31(2):75-102 King AW (1991) Translating models across scales in the landscape. Quantitative Methods in Landscape Ecology:479-517 
Langford WT, Gergel SE, Dietterich TG, Cohen W (2006) Map misclassification can cause large errors in landscape pattern indices: Examples from habitat fragmentation. Ecosystems 9(3):474-488

Lawler JJ, O'Connor RJ, Hunsaker CT, Jones KB, Loveland TR, White D (2004) The effects of habitat resolution on models of avian diversity and distributions: A comparison of two land-cover classifications. Landsc. Ecol. 19(5):517-532

Lechner AM, Jones SD, Bekessy SA (2008) A study on the impact of Scale Dependent Factors on the Classification of Landcover maps. In: Stein A., Shi J., Wietske B. (eds), Quality Aspects in Spatial Data Mining. Chapman and Hall/CRC Press, pp. 315-328 Lechner AM, Langford WT, Jones SD, Gordon A, Bekessy SA (2012) Investigating pattern processes relationships at multiple scales with remote sensing: Differentiating between ecological phenomenon and spatial data artefacts. Ecol. Complex.11(9):91-102 Lechner AM, Stein A, Jones SD, Ferwerda JG (2009) Remote sensing of small and linear features: Quantifying the effects of patch size and length, grid position and detectability on land cover mapping. Remote Sens. Environ. 113(10):2194-2204 Levin SA (1992) The Problem of Pattern and Scale in Ecology. The Ecological Society of America 73(6):1943-1967

Li H, Wu J (2004) Use and misuse of landscape indices. Landsc. Ecol. 19(4):389-399 Manton M, Angelstam P, Mikusiński G (2005) Modelling Habitat Suitability for Deciduous Forest Focal Species - A Sensitivity Analysis using Different Satellite Land Cover Data. Landsc. Ecol. 20(7):827-839

Mayer AL, Cameron GN (2003) Consideration of grain and extent in landscape studies of terrestrial vertebrate ecology. Landsc. Urban Plann. 65(4):201-217 Metzger J (2008) Landscape ecology: perspectives based on the 2007 IALE world congress. Landsc. Ecol. 23(5):501-504 
Moody A, Woodcock CE (1994) Scale-Dependent Errors in the Estimation of Land-Cover Proportions - Implications for Global Land-Cover Datasets. Photogrammetric Engineering and Remote Sensing 60(5):585-594

Nelson A (2001) Analysing data across geographic scales in Honduras: detecting levels of organisation within systems. Agriculture, Ecosystems \& Environment 85(1-3):107131

O'Neill RV, Hunsaker CT, Timmins SP et al (1996) Scale problems in reporting landscape pattern at the regional scale. Landsc. Ecol. 11(3):169-180

O'Neill RV, Johnson AR, King AW (1989) A hierarchical framework for the analysis of scale. Landsc. Ecol. 3(3-4):193-205

Pascual-Hortal L, Saura S (2007) Impact of spatial scale on the identification of critical habitat patches for the maintenance of landscape connectivity. Landsc. Urban Plann. $83(2-3): 176-186$

Pontius Jr RG, Chen H, Thontteh O Multiple scale pattern recognition and the foundation of observation-free statistics. In: Conference Proceedings of the meeting of the American Society for Photogrammetry and Remote Sensing, Baltimore 2005. p. 11 Pontius R, Thontteh O, Chen H (2008) Components of information for multiple resolution comparison between maps that share a real variable. Environ. Ecol. Stat. $15(2): 111-142$

Powell RL, Matzke N, de Souza C et al (2004) Sources of error in accuracy assessment of thematic land-cover maps in the Brazilian Amazon. Remote Sens. Environ. 90(2):221234

Quaife T, Quegan S, Disney M, Lewis P, Lomas M, Woodward FI (2008) Impact of land cover uncertainties on estimates of biospheric carbon fluxes. Global Biogeochemical Cycles 22 
Rae C, Rothley K, Dragicevic S (2007) Implications of error and uncertainty for an environmental planning scenario: A sensitivity analysis of GIS-based variables in a reserve design exercise. Landsc. Urban Plann. 79(3-4):210-217

Remmel TK (2009) Investigating global and local categorical map configuration comparisons based on coincidence matrices. Geographical Analysis 41(2):144-157 Riitters K, Wickham J, O'Neill R, Jones B, Smith E (2000) Global-Scale Patterns of Forest Fragmentation. Conserv. Ecol. 4(2):XV-XVI

Robinson VB (2007) Issues and Challenges of Incorporating Fuzzy Sets in Ecological Modeling. In: Morris A. andKokhan S. (eds), Geographic Uncertainty in Environmental Security, NATO Security through Science Series. Springer Netherlands, pp. 33-51 Saura S (2002) Effects of minimum mapping unit on land cover data spatial configuration and composition. Int. J. Remote Sens. 23(22):4853-4880 Saura S, Castro S (2007) Scaling functions for landscape pattern metrics derived from remotely sensed data: Are their subpixel estimates really accurate? ISPRS Journal of Photogrammetry and Remote Sensing 62(3):201-216 Schmit C, Rounsevell MDA, La Jeunesse I (2006) The limitations of spatial land use data in environmental analysis. Environmental Science \& Policy 9(2):174-188 Smith JH, Stehman SV, Wickham JD, Yang L (2003) Effects of landscape characteristics on land-cover class accuracy. Remote Sens. Environ. 84(3):342-349 Smith JH, Wickham JD, Stehman SV, Yang L (2002) Impacts of patch size and land-cover heterogeneity on thematic image classification accuracy. Photogrammetric engineering and remote sensing 68(1):65-70

Stohlgren TJ, Chong GW, Kalkhan MA, Schell LD (1997) Multiscale sampling of plant diversity: Effects of minimum mapping unit size. Ecol. Appl. 7(3):1064-1074 
Stoms DM, Davis FW, Cogan CB (1992) Sensitivity of wildlife habitat models to uncertainties in GIS data. Photogrammetric Engineering \& Remote Sensing 58(6):843850

Tatem AJ, Lewis HG, Atkinson PM, Nixon MS (2002) Super-resolution land cover pattern prediction using a Hopfield neural network. Remote Sens. Environ. 79(1):1-14 Thompson S, Gergel S (2008) Conservation implications of mapping rare ecosystems using high spatial resolution imagery: recommendations for heterogeneous and fragmented landscapes. Landsc. Ecol. 23(9):1023-1037

Townsend PA, Lookingbill TR, Kingdon CC, Gardner RH (2009) Spatial pattern analysis for monitoring protected areas. Remote Sens. Environ. In Press, Corrected Proof Turner MG (1989) Landscape ecology: the effect of pattern on process. Annu. Rev. Ecol. Syst. 20:171-197

Turner MG (2005) Landscape Ecology: What Is the State of the Science? Annual Review of Ecology, Evolution, and Systematics 36(1):319-344

Turner MG, Gardner RH, O'Neill RV (2001) Landscape Ecology in Theory and Practice Pattern and Process. Springer-Verlag, New York

Vermaat JE, Eppink F, van den Bergh JCJM, Barendregt A, van Belle J (2005) Aggregation and the matching of scales in spatial economics and landscape ecology: empirical evidence and prospects for integration. Ecol. Econ. 52(2):229-237

Wickham JD, Riitters KH (1995) Sensitivity of landscape metrics to pixel size. Int. J. Remote Sens. 16(18):3585-3594

Wiens JA (1989) Spatial scaling in ecology. Funct. Ecol.(3):385-397

Woodcock CE, Strahler AH (1987) The Factor of Scale in Remote-Sensing. Remote Sens. Environ. 21(3):311-332 
Wu J, Gao W, Tueller PT (1997) Effects of changing spatial scale on the results of statistical analysis with landscape data: A case study. Geogr Inform Sci 3:30-41 Wu J, Jelinski DE, Luck M, Tueller PT (2000) Multiscale analysis of landscape heterogeneity: Scale variance and pattern metrics. Geogr Inform Sci 6(1): 6-19 Wu J, Li H (2006) Concepts of scale and scaling. In: Jianguo Wu, Jones K. B., Li H., Louck O. L. (eds), Scaling and uncertainty analysis in ecology: methods and applications. Springer, Dordrecht, Netherlands, pp. 3-15

Wu J, Li H, Jones K, Loucks O (2006) Scaling with known uncertainty: A synthesis. In: Jianguo Wu, Jones K. B., Li H., Louck O. L. (eds), Scaling and uncertainty analysis in ecology: methods and applications. Springer, Dordrecht, Netherlands, pp. 329-346 Wu JG (2004) Effects of changing scale on landscape pattern analysis: scaling relations. Landsc. Ecol. 19(2):125-138

Wu JG, Shen WJ, Sun WZ, Tueller PT (2002) Empirical patterns of the effects of changing scale on landscape metrics. Landsc. Ecol. 17(8):761-782

Zukowskyj PM, Bussell MA, Power C, Teeuw RM (2001) Quantitative accuracy assessment of contextually filtered classified images. Int. J. Remote Sens. 22(16):32033222

Zurell D, Berger U, Cabral JS et al (2010) The virtual ecologist approach: simulating data and observers. Oikos 119(4):622-635 


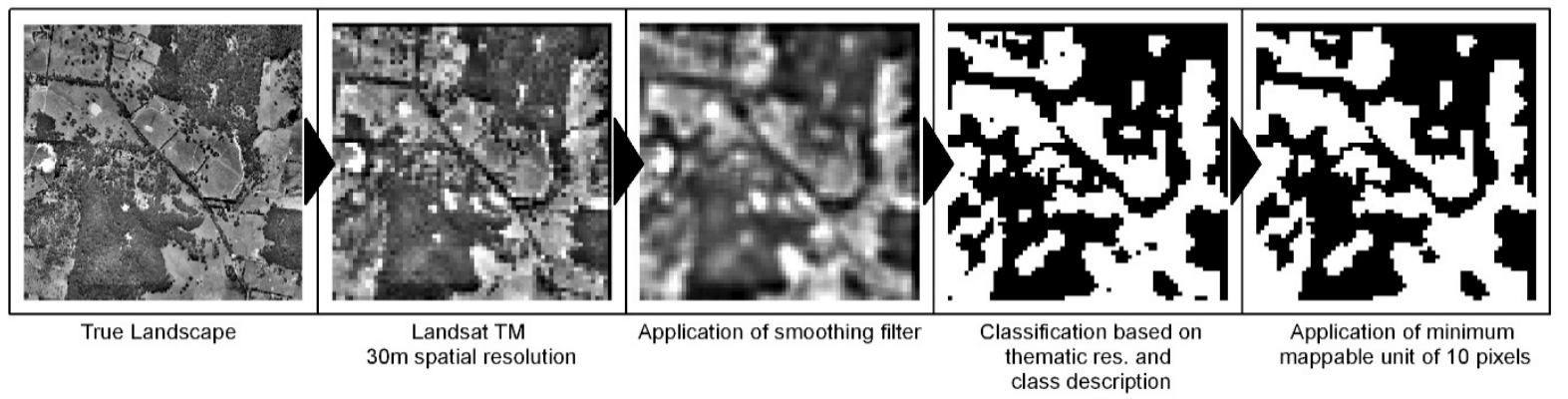

Figure 1 LULC map creation process. Remote sensing data is captured using Landsat TM, pre-processed, classified and post-processed. Spatial uncertainty arises in each processing step. 

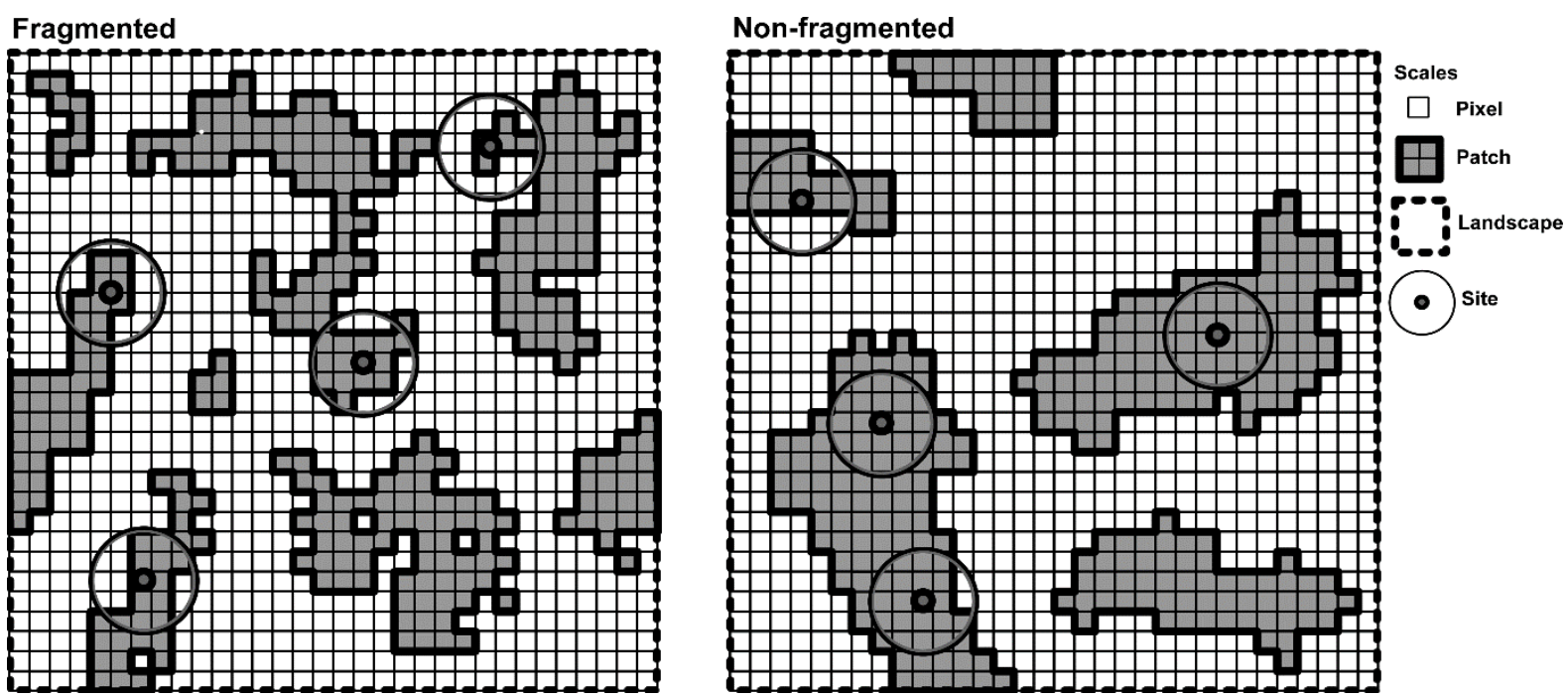

Figure 2 Example of different observation and analysis scales. Ecological phenomena can be measured and analysed using any one of the scales described in the image, from pixels to patches. 


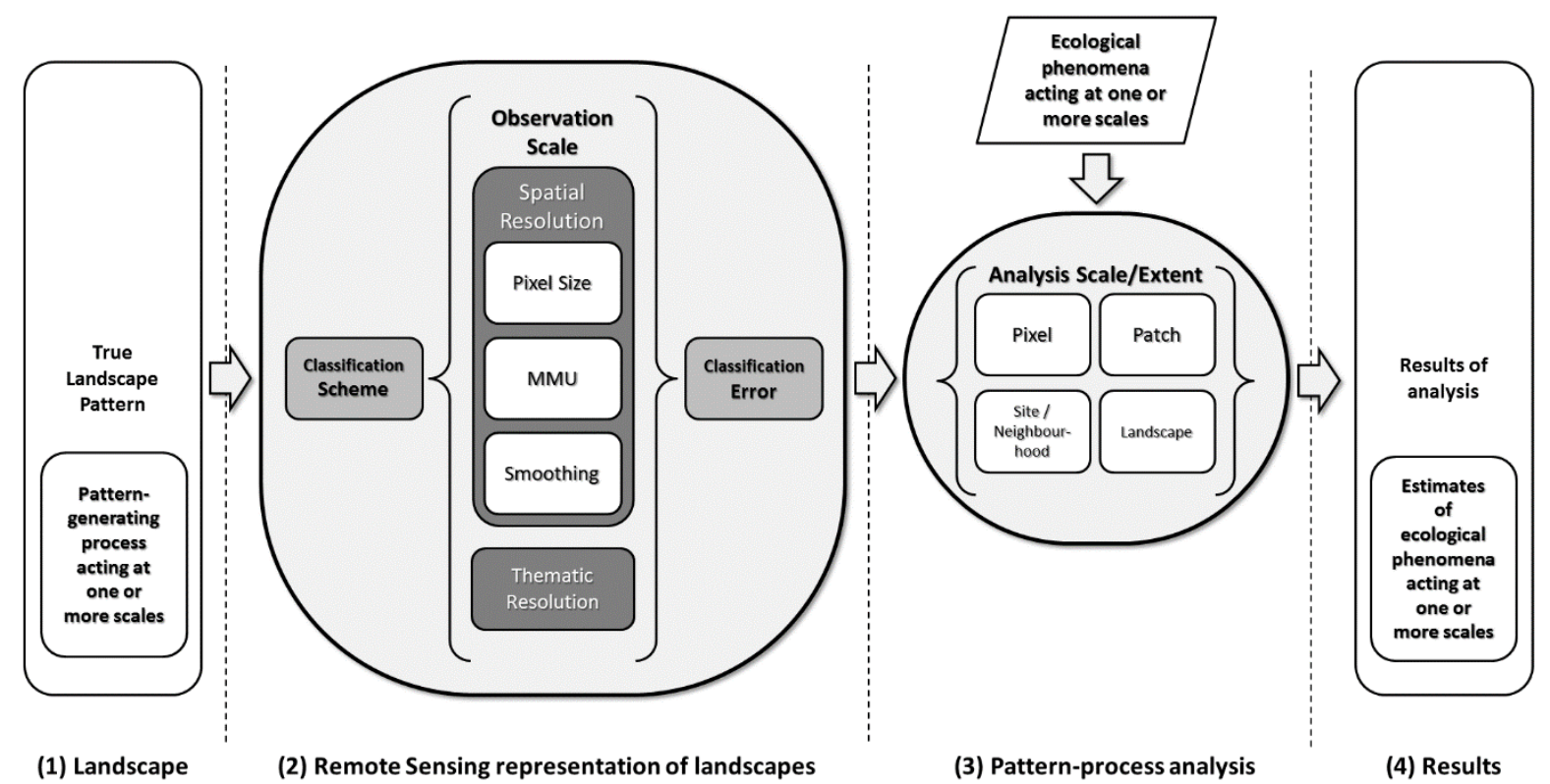

Figure 3 Conceptual relationship describing spatial uncertainty in landscape ecology. Landscapes (1) used in pattern-process analyses characterised by remote sensing data are affected by multiple ways in which the LULC maps are derived (2). These geographic representations of landscapes are the analysed in relation to an ecological phenomenon at a particular analysis scale (3). The results of ecological analyses will be a property of the scale at which a phenomenon operates and the way it is observed and analysed (4). 


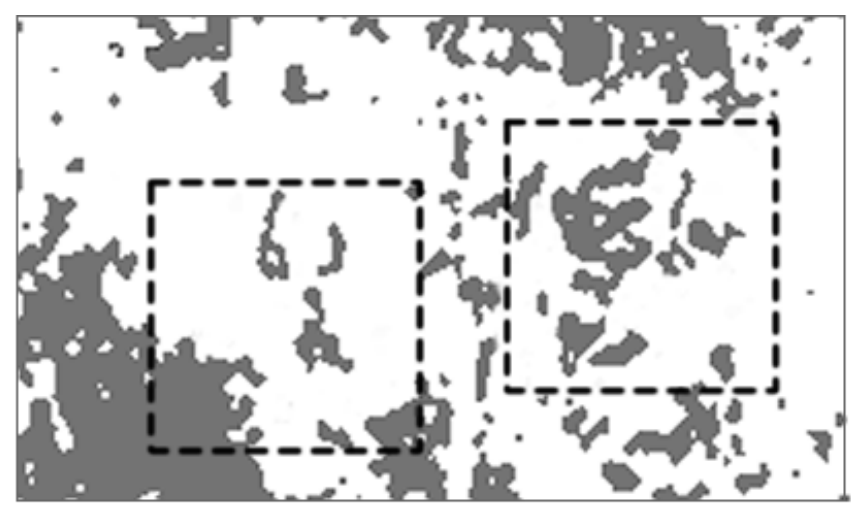

\section{Landscape}

Compare between Landscapes.

Measurement examples:

PATCH: Patch density,

Mean patch area.

PIXEL: Total vegetation area.

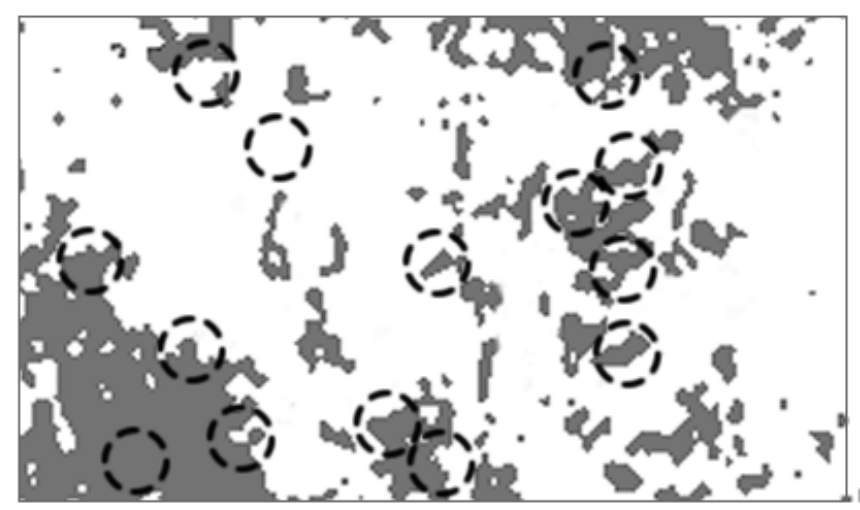

Site

Compare between sites

Measurement examples:

PIXEL: Fraction vegetation coverage.

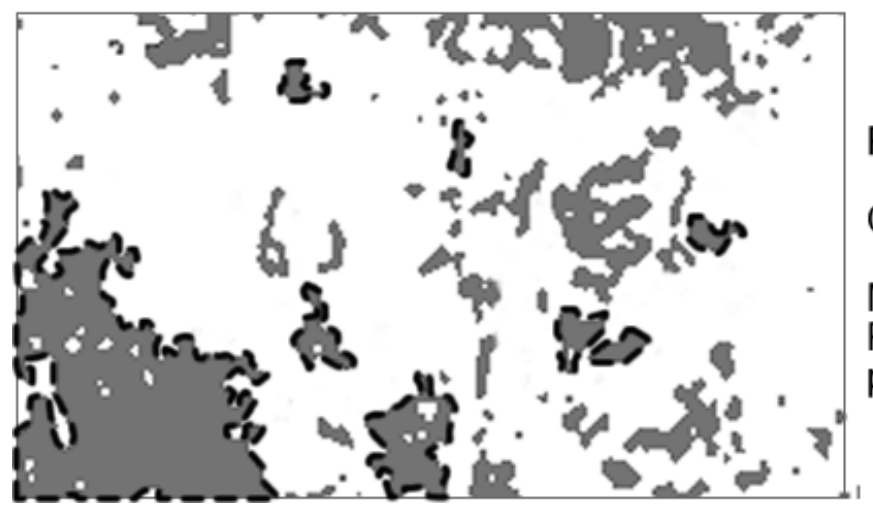

\section{Patch}

Compare between patches

Measurement examples:

PIXEL: Patch area,

perimeter area.

Figure 4 Examples of different organisational levels and the types of measurements used. 


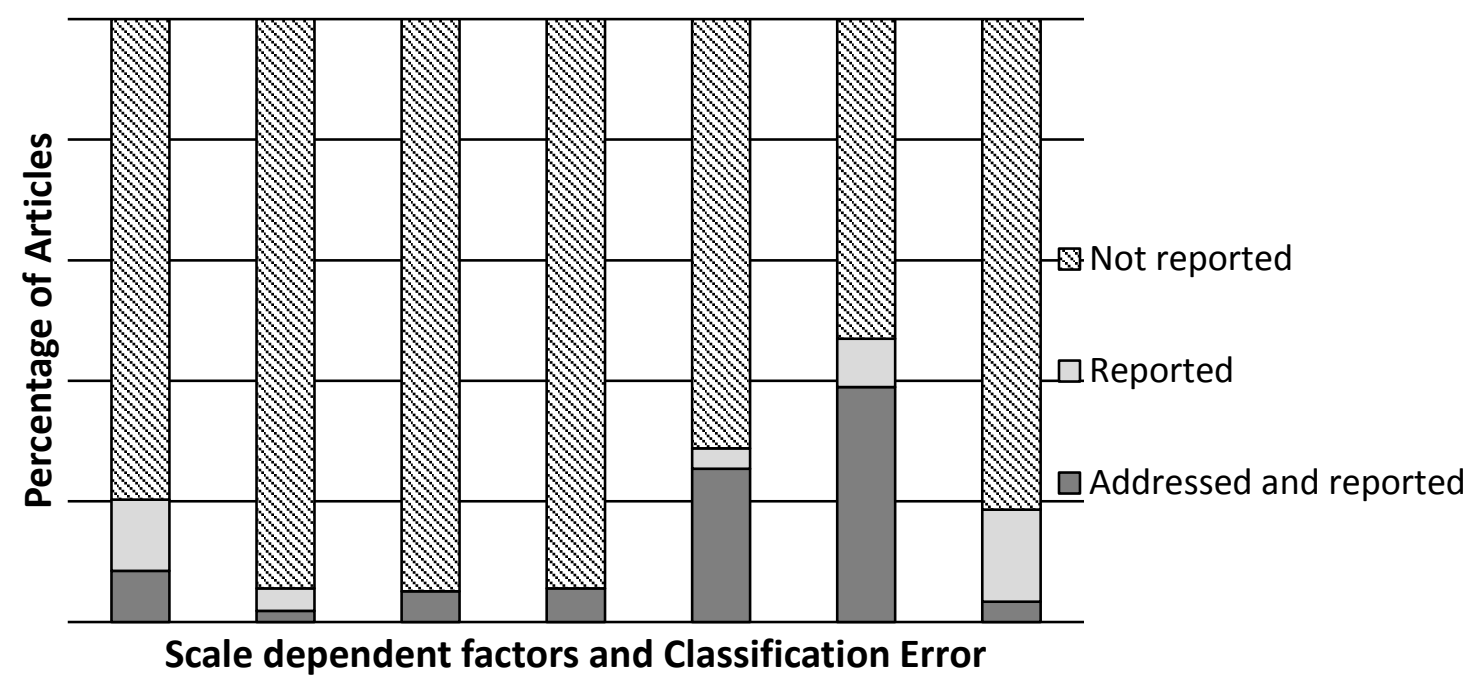

Figure 5 Scale dependent factors and classification error addressed, reported and not reported (pixel, smoothing, extent and classification error, $n=59$; MMU and thematic resolution $\mathrm{n}=54)$. 
Table 1 Summary of spatial data use. *Note some studies used more than one remote sensing dataset or more than one analysis scale thus the total in each category may not add up to $100 \%$.

\begin{tabular}{lll} 
Review category & total & percentage \\
\hline Spatial data sources (n=86) & & \\
$\quad$ Only GIS data & 13 & $15 \%$ \\
RS data & 59 & $69 \%$ \\
$\quad$ No spatial data & 14 & $16 \%$ \\
RS data type (n=59)* & & \\
$\quad$ Binary & 15 & $25 \%$ \\
$\quad$ Multi-class & 40 & $68 \%$ \\
$\quad$ Continuous & 7 & $12 \%$ \\
Readily available data used (n=59)* & & \\
$\quad$ Corine & 2 & $3 \%$ \\
$\quad$ NLCD & 6 & $10 \%$ \\
$\quad$ Other generic & 21 & $36 \%$ \\
$\quad$ Non-generic data & 38 & $64 \%$ \\
Analysis scale used (n=59)* & & \\
site & 17 & $29 \%$ \\
patch & 13 & $22 \%$ \\
landscape & 31 & $53 \%$ \\
Acquisition method used (n=59)* & & \\
$\quad$ Aerial photography & 31 & $53 \%$ \\
Landsat (MSS / TM / ETM+) & 27 & $46 \%$ \\
NOAA- AVHRR & 2 & $3 \%$ \\
Other & 14 & $24 \%$
\end{tabular}

